\title{
Effects of fish oil and Tamoxifen on preneoplastic lesion development and biomarkers of oxidative stress in the early stages of $\mathrm{N}$-methyl-N-nitrosourea-induced rat mammary carcinogenesis
}

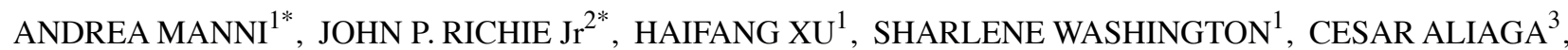 \\ TIMOTHY K. COOPER ${ }^{4}$, RICHARD BRUGGEMAN ${ }^{5}$, ARUNANGSHU DAS ${ }^{3}$, BOGDAN PROKOPCZYK ${ }^{6}$, \\ ANA CALCAGNOTTO ${ }^{2}$, NEIL TRUSHIN ${ }^{6}$, REBECCA DICKINSON ${ }^{2}$, JASON LIAO $^{2}$, \\ MICHAEL F. VERDERAME ${ }^{1}$ and KARAM EL-BAYOUMY ${ }^{3}$ \\ Departments of ${ }^{1}$ Medicine, ${ }^{2}$ Public Health Sciences, ${ }^{3}$ Biochemistry and Molecular Biology, \\ ${ }^{4}$ Comparative Medicine, ${ }^{5}$ Pathology and ${ }^{6}$ Pharmacology, Pennsylvania State University College \\ of Medicine, Milton S. Hershey Medical Center, 500 University Drive, Hershey, PA 17033, USA
}

Received May 3, 2011; Accepted June 14, 2011

DOI: $10.3892 /$ ijo.2011.1133

\begin{abstract}
Epidemiologic studies on the protective role of omega-3 fatty acids (n:3) on breast cancer prevention remain inconclusive but studies in preclinical models provide more positive outcome. However, the mechanisms accounting for the protective effect of n:3 are not defined. In the present study, conducted in the N-methyl-N-nitrosourea-induced rat mammary carcinogenesis model, we examined the effects of n:3 individually and in combination with the anti-estrogen Tamoxifen (Tam) on a comprehensive panel of systemic and preneoplastic mammary gland restricted biomarkers which may be critical in the progression to invasive cancer. We observed that fish oil (FO) rich diets significantly reduced Ki67 expression in hyperplastic lesions, while cleaved caspase- 3 expression was not affected. Dietary FO and/or Tam did not have major effects on systemic oxidative stress biomarkers, based on oxidative damage to DNA measured as 8-hydroxy-2-deoxyguanosine (8-OH-dG) and lipid peroxidation assessed as thiobarbituric acid reactive substances (TBARS). Tissue levels of 8-isoprostane, on the other hand, were markedly reduced $(\mathrm{p}<0.0001)$ in FO-fed rats, possibly as a result of FO-induced depletion of arachidonic acid in the mammary gland. These results suggest that the protective effect of $n: 3$ in this experimental system is not mediated by changes in the levels of oxidative stress but may result from suppression of arachidonic acid-specific pathways.
\end{abstract}

Correspondence to: Dr Andrea Manni, Division of Endocrinology, H044, Hershey Medical Center, 500 University Drive, P.O. Box 850, Hershey, PA 17033, USA

E-mail: amanni@hmc.psu.edu

*Contributed equally.

Key words: fish oil, Tamoxifen, oxidative stress, preneoplastic mammary lesions, breast cancer prevention

\section{Introduction}

Our laboratories are interested in testing the value of combining n:3 fatty acids and antiestrogens as a safe and effective chemopreventive strategy for breast cancer. We have reported that the administration of a fish oil (FO) rich diet (17\% FO + 3\% $\mathrm{CO}, \mathrm{n} 3: \mathrm{n} 6=2.3)$ potentiated the chemopreventive action of Tamoxifen (Tam) in a prepubertal model of rat mammary carcinogenesis (1). Our data suggested that a reduction in the level of oxidative stress may have contributed to the added antitumor action of the FO rich diet in the presence of Tam (1). Since, however, our measurements were performed in established tumors, it was difficult to determine whether the findings related to carcinogenesis or were a consequence of tumor development. Therefore, the experiments reported here were designed to gain insight into the mechanisms of antitumor actions of $\mathrm{FO}$ in the presence and in the absence of Tam treatment by assessing its effects on mammary gland histology as well as a variety of tissue and host-related biomarkers at early time-points prior to the development of palpable tumors.

In addition to the high FO diet (n3:n6=2.3) tested in our previous report, we also tested a diet with equal amounts of $\mathrm{FO}$ and $\mathrm{CO}(10 \% \mathrm{FO}+10 \% \mathrm{CO}, \mathrm{n} 3: \mathrm{n} 6=0.56)$ since some investigators have reported that a ratio of $n 3: n 6$ of $1: 1$ or $1: 2$ is optimal for inhibition of MNU-induced mammary carcinogenesis $(2,3)$. Finally, prior to testing the effects of FO rich diets and/or Tamoxifen on MNU-induced mammary carcinogenesis, we deemed it important to test the effects of MNU alone on mammary gland histology and select biomarkers over the same time frame.

\section{Materials and methods}

Diets. Modified AIN-76A diets were designed by TestDiet. All dietary ingredients were obtained from Dyets except for Virginia Prime Gold fish oil (omega protein). The diets were prepared monthly in our laboratory, flushed with nitrogen, and 
stored at $4^{\circ} \mathrm{C}$ until use. All the diets were isocaloric $(4.78 \mathrm{kcal} / \mathrm{g})$. The percent of energy from proteins, carbohydrates, and fat were 20, 42 and $38 \%$ respectively. The compositions of the diets as well as the percent of energy derived from saturated, monounsaturated, and polyunsaturated fatty acids (totaling 38\%) are shown in Table I. The calculated n-3:n- 6 ratio was 0.005 in the $20 \% \mathrm{CO}$ diet, 2.30 in the $17 \% \mathrm{FO}+3 \% \mathrm{CO}$ diet, and 0.56 in the $10 \% \mathrm{FO}+10 \% \mathrm{CO}$ diet.

\section{Experimental model and design}

Time course study of MNU effects on mammary gland specific and systemic biomarkers. Female Sprague Dawley rats with 10 female pups were purchased from Charles River Laboratories International Inc. All animal studies were approved by the Institutional Animal Care and Use Committee (IACUC) of the Pennsylvania State University College of Medicine. At day 20 of age, they were weighed and placed on a modified AIN-76A diet containing $20 \%$ CO. At 21 day of age, they were injected i.p. with either normal saline or $50 \mathrm{mg} \mathrm{MNU} / \mathrm{kg}$ body weight. Groups of rats matched for weight ( $n=13-18$ per group) were sacrificed by $\mathrm{CO}_{2}$ asphyxiation after 2 and 24 h, 21, 28 and 35 days. In this experimental system, we have previously shown that the rats develop palpable tumors between 5 and 8 weeks following MNU administration (1). Rats followed for 21 days or longer were weighed weekly. Blood was obtained by cardiac puncture and processed for separation of serum, plasma and red blood cells, using EDTA as an anticoagulant. The two abdominal inguinal mammary fat pads were carefully excised from each rat and either snap frozen in liquid nitrogen or spread onto clean 50x75 mm pre-labelled microscope slides (Brain Research Laboratories) for whole mount preparation. The slides were left out for 4-5 min to allow the mammary fat pad to tack on, and then prepared as previously described $(1,4)$. The mammary fat pads were processed for routine histologic analysis and IHC as previously reported $(1,4)$.

Time course study of the individual and combined effects of fish oil rich diets and Tamoxifen on mammary gland and systemic biomarkers. Following i.p. administration of MNU $(50 \mathrm{mg} / \mathrm{kg} / \mathrm{BW})$ at day 21 of age, groups of rats matched for weight were randomly assigned to one of the following experimental interventions: i) $20 \%$ CO; ii) $20 \% \mathrm{CO}+$ Tam $100 \mu \mathrm{g} / \mathrm{kg}$ s.c. $5 \mathrm{~d} /$ week; iii) $17 \% \mathrm{FO} / 3 \% \mathrm{CO}$; iv) $17 \% \mathrm{FO} / 3 \% \mathrm{CO}+\mathrm{Tam}$ $100 \mu \mathrm{g} / \mathrm{kg}$ s.c. $5 \mathrm{~d} /$ week; v) $10 \% \mathrm{FO} / 10 \% \mathrm{CO}$; vi) $10 \% \mathrm{FO} / 10 \%$ $\mathrm{CO}+$ Tam $100 \mu \mathrm{g}$ s.c. $5 \mathrm{~d} /$ week. Within each experimental arm, separate groups of rats were sacrificed by $\mathrm{CO}_{2}$ asphyxiation after 24 h, 21, 28 and 35 days. Rats followed for 21 days or longer were weighed weekly. Blood and inguinal mammary fat pads were collected and processed for biomarkers analysis as described above.

Immunohistochemistry for Ki67 and cleaved caspase-3. Immunohistochemistry for Ki67 and cleaved caspase-3 was done as previously described by us (1) using a monoclonal rat and mouse antibody for Ki67 (Dako Cytomation) and a rabbit polyclonal antibody for cleaved caspase-3 (Cell Signaling Technology). Scoring was done by one of us (TKC) blinded to the treatment by counting the number of positively stained cells in three replicate $\mathrm{x} 400$ fields from the same section. All sections were counterstained with hematoxylin to allow verifi- cation of correct histologic categorization of each field scored for immunohistochemistry. Representative immunostains for Ki67 and cleaved caspase- 3 in a benign proliferative lesion are shown in Fig. 1.

Measurement of GSH, glutathione peroxidase (GPX), isoprostane and malondialdehyde measured as thiobarbituric reactive substances (TBARs) in the mammary glands. For measurement of GPX, isoprostane and TBARS, mammary fat pads were removed from liquid nitrogen and processed by homogenization $(10 \%, \mathrm{w} / \mathrm{v})$ in ice cold $10 \mathrm{mM}$ HEPES, $\mathrm{pH} 7.5,0.01 \%(\mathrm{w} / \mathrm{v})$ BHT, $280 \mathrm{mM}$ manitol using an all glass Ten Broeck homogenizer. Homogenates were centrifuged at $1600 \mathrm{~g}$ for $15 \mathrm{~min}$ at $4^{\circ} \mathrm{C}$ and supernatants were stored at $-80^{\circ} \mathrm{C}$ until analysis. Protein concentration was measured by the bicinchoninic acid procedure (Pierce, Rockford, IL). GPX activity was determined as described previously, using cumene hydroperoxide as a substrate (5) modified for use in 96-well plates. 8-Isoprostane was measured by immunoassay (EIA, Cayman Chemical Co., Ann Arbor, MI). TBARS were measured spectrophometrically using a commercially available kit (Cayman Chemical Co.).

For analysis of GSH, mammary fat pads were removed from liquid nitrogen and processed by homogenization (10\%, $\mathrm{w} / \mathrm{v}$ ) in ice cold 5\% (w/v) metaphosphoric acid (MPA) using an all glass Ten Broeck homogenizer. Homogenates were centrifuged at 14,000 $\mathrm{g}$ for $3 \mathrm{~min}$ and acid soluble supernatants were analyzed for free GSH levels by an enzymatic recycling method as described previously (6).

Measurement of 8-hydroxy-2'-deoxyguanosine (8-OHdG) in the mammary glands. Mammary glands were removed from liquid nitrogen and homogenized, nuclear pellets obtained and DNA isolated using a QIA amp DNA Minikit (Qiagen, Valencia, CA) according to the manufacturer's instructions. After measuring DNA concentration, DNA was diluted 1/10 with sodium acetate $\mathrm{pH} 5.2$ and ethanol ( $2 \mathrm{x}$ volume), and placed at $-80^{\circ} \mathrm{C}$ for $1 \mathrm{~h}$. DNA was centrifuged at $6000 \mathrm{~g}$ for $5 \mathrm{~min}$ at $4^{\circ} \mathrm{C}$, washed twice in $70 \%$ ethanol and resuspended in $10 \mathrm{mM}$ Tris buffer $\mathrm{pH} 8.0$ containing $1 \mathrm{mM}$ EDTA at final concentration of $2 \mu \mathrm{g} / \mu \mathrm{l}$. For enzymatic digestion, $15 \mu \mathrm{l}$ of $200 \mathrm{mM}$ sodium acetate $\mathrm{pH} 5.2$ containing $6 \mathrm{U}$ nuclease P1 were added to $100 \mu \mathrm{g}$ DNA, and incubated at $37^{\circ} \mathrm{C}$ for $30 \mathrm{~min}$ under nitrogen. After addition of $15 \mu \mathrm{l}$ of $1 \mathrm{M}$ Tris buffer pH 7.4 containing $2 \mathrm{U}$ of alkaline phosphatase, samples were incubated at $37^{\circ} \mathrm{C}$ for $30 \mathrm{~min}$ under nitrogen. Resulting digested DNA was ultra-filtered using Amicon Ultra- $0.5 \mathrm{ml}$ centrifugal filters (Millipore, Billerica, MA) and centrifuging at $6000 \mathrm{~g}$ for $10 \mathrm{~min}$. 8-OHdG was determined by immunoassay (Cayman Chemical Co.).

Analysis offatty acids, GSH and protein carbonyls. Total fatty acid levels in plasma and mammary tissues were determined by the direct one-step transesterification method of Lepage and Roy (7) with resulting methylated fatty acids being analyzed by gas chromatography equipped with flame ionization detection as described previously (1). The identification of fatty acid methyl esters was accomplished by comparison with the relative retention time of standards. Quantification was based on internal standard calculations as compared to calibration analyses with authentic standards. 
Table I. Composition of experimental AIN-76A diets.

\begin{tabular}{|c|c|c|c|c|c|c|}
\hline \multirow[b]{2}{*}{ Ingredients } & \multicolumn{2}{|c|}{$(20 \% \mathrm{CO})$} & \multicolumn{2}{|c|}{$(17 \% \mathrm{FO}, 3 \% \mathrm{CO})$} & \multicolumn{2}{|c|}{$(10 \% \mathrm{FO}, 10 \% \mathrm{CO})$} \\
\hline & gms & $\%$ & gms & $\%$ & gms & $\%$ \\
\hline Mineral mix & 616.5 & 4.11 & 616.5 & 4.11 & 616.5 & 4.11 \\
\hline Cellulose & 885.0 & 5.90 & 885.0 & 5.90 & 885.0 & 5.90 \\
\hline Casein & 3525.0 & 23.50 & 3525.0 & 23.50 & 3525.0 & 23.50 \\
\hline Dextrose & 1353.0 & 9.02 & 1353.0 & 9.02 & 1353.0 & 9.02 \\
\hline Vitamin mix & 177.0 & 1.18 & 177.0 & 1.18 & 177.0 & 1.18 \\
\hline DL-methionine & 52.5 & 0.35 & 52.5 & 0.35 & 52.5 & 0.35 \\
\hline Choline-bitartrate & 36.0 & 0.24 & 36.0 & 0.24 & 36.0 & 0.24 \\
\hline Corn oil & 3000.0 & 20.00 & 450.0 & 3.00 & 1500.0 & 10.00 \\
\hline Fish oil & 0.0 & 0.00 & 2550.0 & 17.00 & 1500.0 & 10.00 \\
\hline Corn starch & 5355.0 & 35.70 & 5355.0 & 35.70 & 5355.0 & 35.70 \\
\hline Total & 15000 & 100.00 & 15000 & 100.00 & 15000 & 100.00 \\
\hline Saturated fatty acid $\%$ & 4.86 & & 10.49 & & 8.17 & \\
\hline Monounsaturated fatty acid \% & 9.98 & & 9.35 & & 9.61 & \\
\hline Polyunsaturated fatty acid $\%$ & 22.83 & & 17.84 & & 19.90 & \\
\hline
\end{tabular}
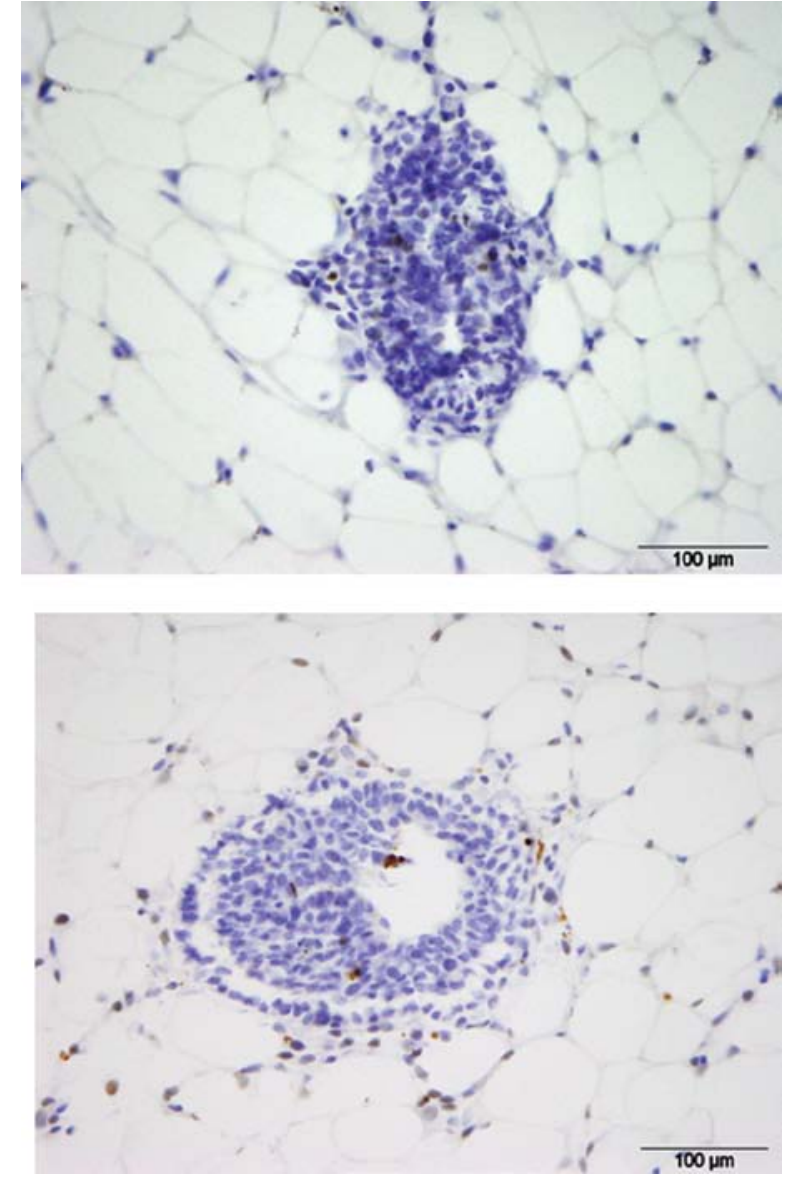

Figure 1. Immunohistochemistry of a moderate intraductal proliferation (IDP) lesion showing positive nuclear staining for Ki67 in proliferating cells (upper panel) and positive staining for cleaved caspase-3 in apoptotic cells and apoptotic bodies (lower panel).

Plasma protein carbonyls were determined spectrophotometrically by using the 2,4-dinitrophenylhydrazine
(DNPH)-labeling procedure as described previously (8). Levels of free GSH and protein-bound GSH, also markers of oxidative stress (9) were analyzed in metaphosphoric acid extracts of whole blood by an enzymatic recycling method as described previously (6).

Statistical analysis. Summary statistics are provided for the outcome measurements for different experimental conditions defined by diet groups, $\mathrm{MNU}^{+}$vs. MNU-, Tamoxifen vs. non Tamoxifen, and time in time course studies. The general statistical methods are regression analysis to study the dependence of these outcome variables on different experimental conditions. Different regression methods are used for different data sets. We summarize the methods used for each of the tables and figures presented in Results (Table II).

Note that ordinal logistic regression is also called proportional odds model. For linear regressions, data transformation (such as square root or log) was performed when necessary. Random effects models were used for Fig. 5 for the repeated measurements of weight. The analysis is conducted using SAS Proc Mixed and Proc logistic. All tests are two-sided.

\section{Results}

MNU time course study. MNU administration caused a $15 \%$ reduction in weight gain of the rats $(\mathrm{p}<0.01)$ (data not show) as previously reported (10). The time-dependent effects of MNU administration on mammary gland development are summarized in Table III. At day 21 post-MNU injection, no differences in histology were noted between MNU-treated and control rats. By day 28, the odds ratio for MNU-treated rats to have more proliferative histologies over control was 3.52 $(\mathrm{p}<0.0001)$ and rose to 7.7 by day $35(\mathrm{p}<0.0001)$. Of interest, among the control rats, the odds ratio of having less proliferative histologies significantly increased over time (3.1 on day 28 and 9.8 on day 35 over day $21, \mathrm{p}<0.001$ ). 
Table II. Methods used for each of the Tables and Figures presented in Results.

\begin{tabular}{llll}
\hline Table/Figure & \multicolumn{1}{c}{ Statistical methods } & \multicolumn{1}{c}{ Outcome variable } & Predictors \\
\hline Table III & Ordinal logistic regression & Histology grade & MNU and time \\
Table IV & Analysis of variance & Fatty acid concentration & Diet groups \\
Table V & Ordinal logistic regression & Histology grade & Diet, TAM and time \\
Figure 2 & Linear regression & Ki67, cleaved caspase-3 & Histology, MNU and time \\
Figure 3 & Linear regression & Blood GSH, protein carbonyls & Time and MNU \\
Figure 4 & Linear regression & Mammary GSH & Time and MNU \\
Figure 5 & Random effects linear model & Body weight & Time, diet and TAM \\
Figure 6 & Linear regression & Ki67, cleaved caspase-3, & Diet, TAM and histology \\
Figure 7 & Linear regression & Protein carbonyls, GSH, 8-OHdG, & Diet and time \\
Figure 8 & Linear regression & TBARS, 8-isoprostane & Diet and time \\
\hline
\end{tabular}

Table III. Evolution of mammary gland histology over time in the absence and in the presence of MNU administration. ${ }^{\mathrm{a}}$

\begin{tabular}{|c|c|c|c|c|c|c|}
\hline \multirow[b]{3}{*}{ Histology $\mathrm{y}^{\mathrm{b}}$} & \multicolumn{6}{|c|}{ Time after MNU administration } \\
\hline & \multicolumn{2}{|c|}{ Day 21} & \multicolumn{2}{|c|}{ Day 28} & \multicolumn{2}{|c|}{ Day 35} \\
\hline & $-\mathrm{MNU}$ & $+\mathrm{MNU}$ & $-\mathrm{MNU}$ & $+\mathrm{MNU}$ & $-\mathrm{MNU}$ & $+\mathrm{MNU}$ \\
\hline Normal & 5 & 3 & 11 & 4 & 22 & 6 \\
\hline Mild IDP & 7 & 2 & 9 & 7 & 9 & 10 \\
\hline Moderate IDP & 13 & 21 & 11 & 13 & 6 & 12 \\
\hline Florid IDP & 8 & 8 & 1 & 4 & 0 & 3 \\
\hline DCIS & 0 & 0 & 0 & 1 & 0 & 0 \\
\hline AC-DCIS & 0 & 0 & 0 & 0 & 0 & 1 \\
\hline $\mathrm{AC}$ & 0 & 0 & 0 & 0 & 0 & 4 \\
\hline
\end{tabular}

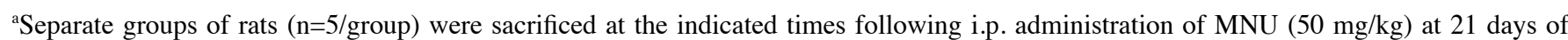
age. Parallel groups of control rats not injected with MNU were sacrificed at the same time. Two abdominal inguinal mammary fat pads were excised from each rat and processed for histologic analysis as described in Materials and methods. Between 29 and 37 sections/group were analyzed and histologically classified as shown. The numbers represent the number of histologic subtypes scored within each group. See text for statistical analysis. ${ }^{b}$ IDP, intraductal proliferation; DCIS, ductal carcinoma in situ; AC-DCIS, invasive adenocarcinoma with an in situ component; AC, invasive adenocarcinoma.

Effect of MNU on Ki67 and cleaved caspase-3 expression. As can be seen in Fig. 2A, Ki67 expression progressively increased as benign lesions became more proliferative (mild $\rightarrow$ moderate $\rightarrow$ florid hyperplasia $)(\mathrm{p}=0.0001)$ and was highest in DCIS and adenocarcinomas. Expression of cleaved caspase-3 was also higher in the more proliferative benign lesions ( $p=0.0001)$ (Fig. 2B) but did not increase further in DCIS and adenocarcinomas, thus pointing to the balance in favor of proliferation over apoptosis in cancer. No difference in either Ki67 or cleaved caspase-3 expression was observed for similar lesions between MNU treated and control rats (Fig. 2).

Effect of MNU on free and bound GSH and protein carbonyl levels in blood. To examine the short- and long-term effects of MNU on systemic biomarkers of antioxidant status and oxidative stress, free and protein bound GSH concentrations in blood and protein carbonyl concentrations in plasma were measured at different time-points from $2 \mathrm{~h}$ to 35 days after administration of MNU or vehicle (Fig. 3A). One day after MNU administration, GSH levels in blood were decreased by $16 \%$ compared to control and remained significantly lower by $12-23 \%$ throughout the remaining 35 day study period ( $\mathrm{p} \leq 0.006)$. Protein bound GSH in blood was not significantly changed by MNU except at 1 day and 28 days where a significant decrease was observed. The ratio of bound:free GSH was unchanged by MNU treatment suggesting that MNU had no effect on the redox status of GSH. This latter result was consistent with the results for plasma protein carbonyls where no MNU effects were observed (Fig. 3B). However, levels of protein carbonyls did tend to decrease over time in both $\mathrm{MNU}$ treated and untreated groups $(\mathrm{p}<0.05)$. Altogether, these finding suggest that MNU has no major impact on overall levels of oxidative stress as measured by these systemic biomarkers. 

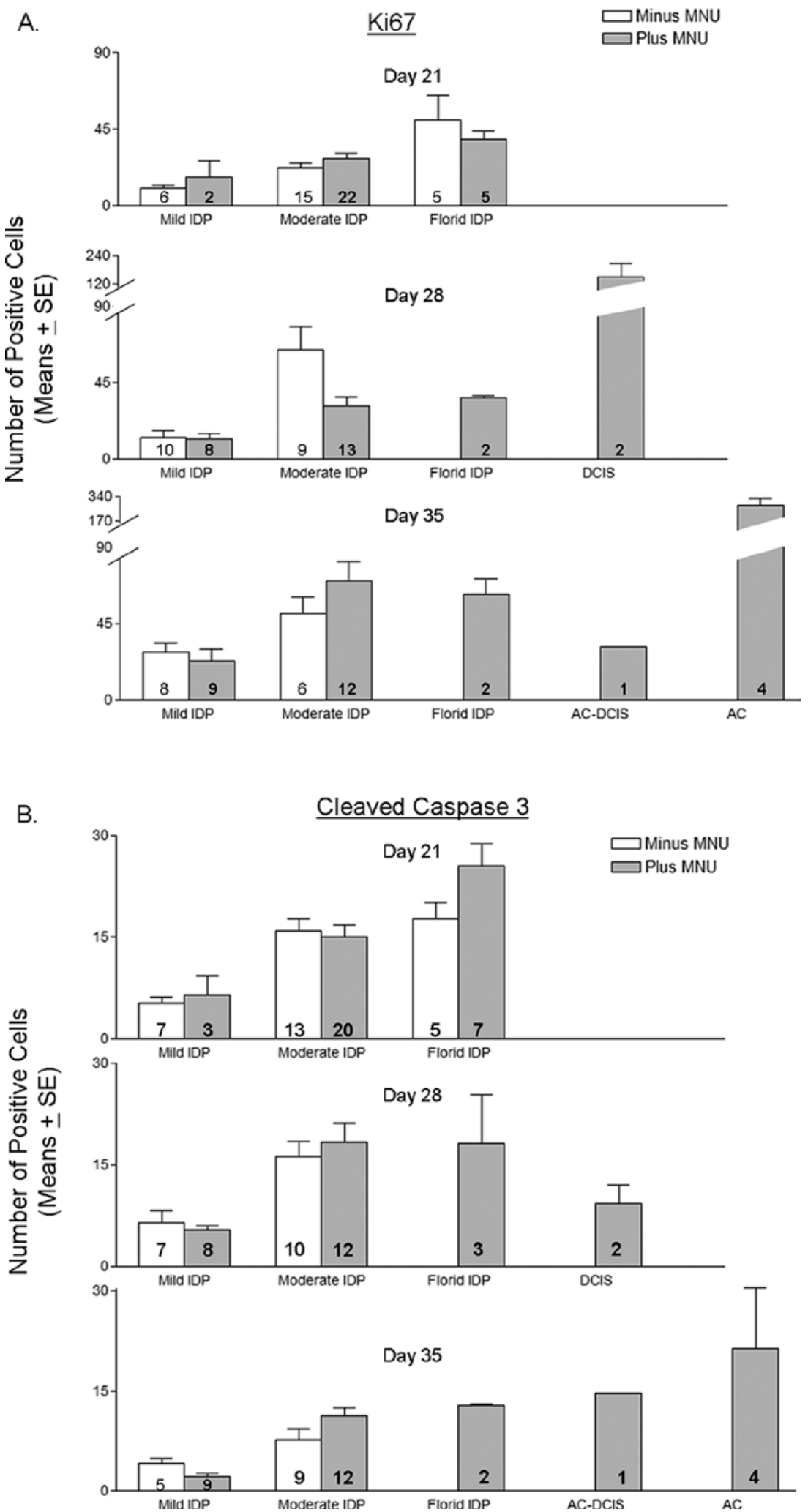

Figure 2. Time-dependent changes in the expression of Ki67 (A) and cleaved caspase-3 (B) by different histologic subtypes in the absence and in the presence of MNU administration. Separate groups of rats $(n=5)$ were sacrificed at the indicated times following MNU administration. Control rats not injected with MNU were sacrificed at the same time. Two abdominal inguinal mammary fat pads were excised from each rat and processed for immunohistochemistry as described in Materials and methods. The numbers within the bars represent the numbers of lesions, each examined in three replicate sections. See text for statistical analysis.

Effects of MNU on mammary GSH. To determine if MNU administration impacted the status of the major intracellular antioxidant GSH in the mammary gland, we measured the levels of GSH in inguinal mammary fat pads of MNU-treated and control rats (Fig. 4). A time-dependent depletion and repletion of GSH levels was observed as a result of MNU treat- 
A

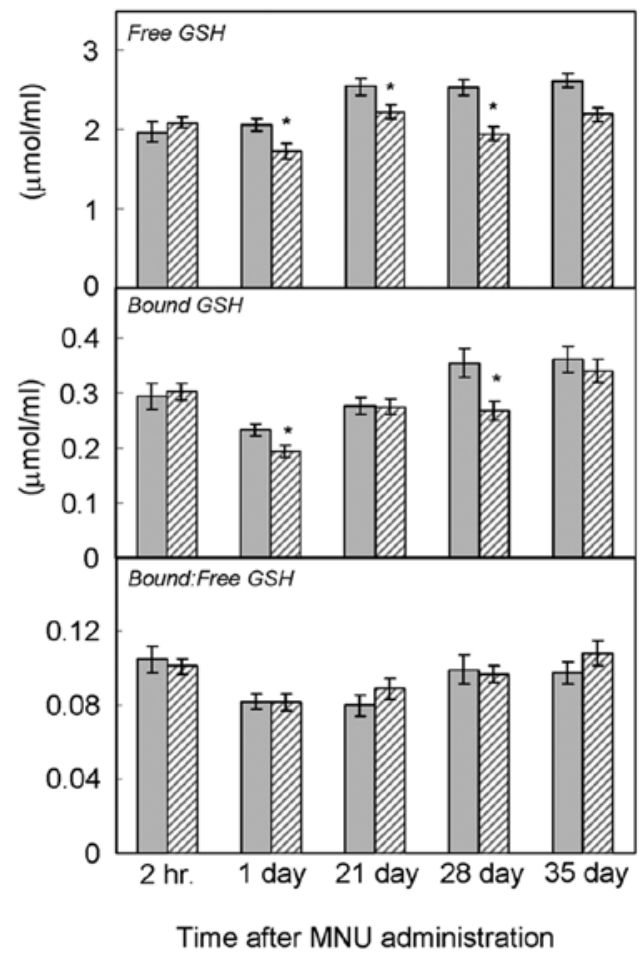

B
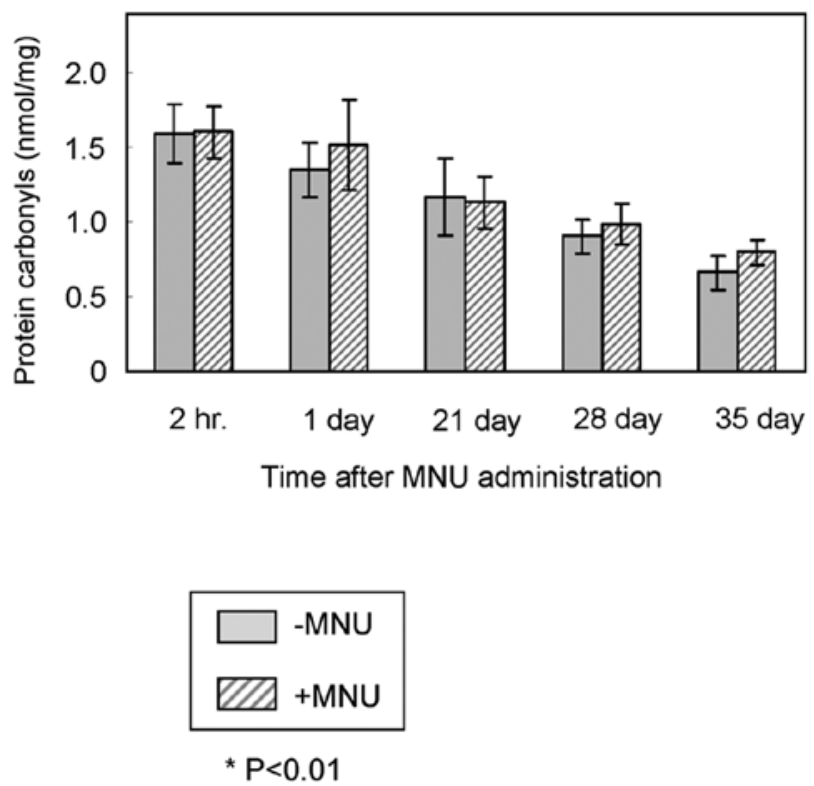

Figure 3. Effect of MNU on blood-free and bound GSH and plasma protein carbonyls. Groups of rats were sacrificed at the indicated times following MNU administration and blood was obtained by cardiac puncture using EDTA and an anticoagulant. Control rats not injected with MNU were sacrificed at the same time. (A) Glutathione (free and bound) was determined in MPA extracts of whole blood ( $\mathrm{n}=13$ per group) and, (B) protein carbonyls were determined in plasma $(\mathrm{n}=4$ per group). Methodological details are provided in Materials and methods. Bars represent mean \pm SEM.

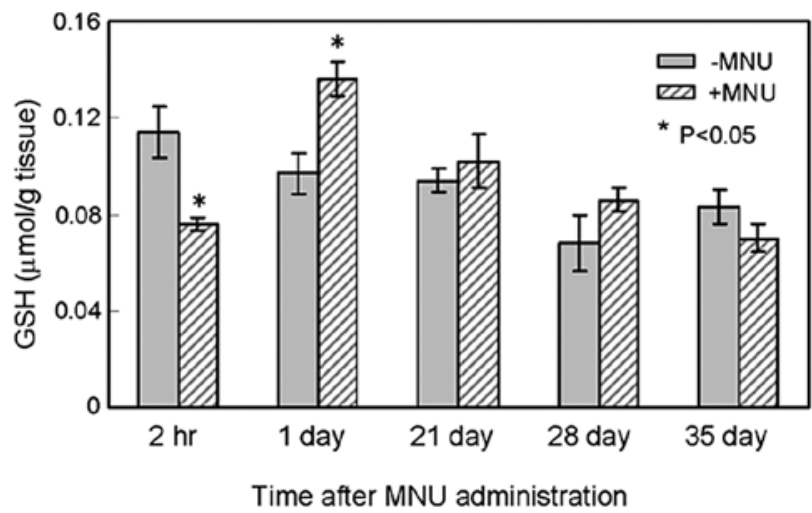

Figure 4. Effect of MNU on mammary GSH levels. Groups of rats $(n=3)$ were sacrificed at the indicated times following MNU administration. Control rats not injected with MNU were sacrificed at the same time. A single abdominal inguinal mammary from each rat was excised and processed by homogenization in MPA. Acid soluble fractions were removed and analyzed for free GSH. Methodological details are provided in Materials and methods. Bars represent mean \pm SEM.

ment. Two hours after MNU administration, GSH levels were depleted $33 \%$, after which time, levels rebounded to $139 \%$ of control by $24 \mathrm{~h}(\mathrm{p}<0.05)$. By 21 days and thereafter, no significant differences were observed from controls.

Time course study with FO rich diets and/or Tamoxifen. All diets were well tolerated with similar weight gain over time (Fig. 5).

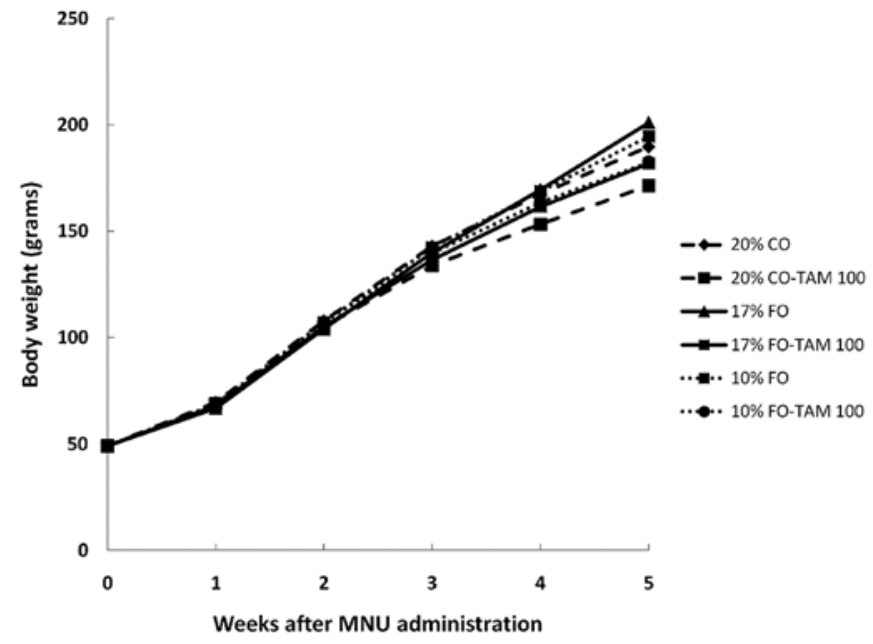

Figure 5. Effect of dietary interventions and Tamoxifen administration on body weight. See text for statistical analysis.

Tamoxifen administration significantly $(\mathrm{p}<0.01)$ suppressed weight gain (Fig. 5), an effect previously shown by us (1) and other investigators $(11,12)$ not to reflect toxicity from the drug.

Effect of FO on fatty acid concentrations. To examine the impact of dietary fish oil on fatty acid profiles in mammary tissue and plasma, we measured the levels of individual fatty acids expressed as both absolute concentrations (per ml of 
Table IV. Effect of fish oil on plasma and mammary fatty acid concentrations at termination.

\begin{tabular}{|c|c|c|c|c|c|c|}
\hline \multirow[b]{2}{*}{ Fatty acid } & \multicolumn{3}{|c|}{ Absolute concentration $^{\mathrm{a}}$} & \multicolumn{3}{|c|}{ Relative concentration $^{\mathrm{a}}$} \\
\hline & $20 \% \mathrm{CO}$ & $\begin{array}{l}10 \% \mathrm{FO} \\
(\mu \mathrm{mol} / \mathrm{l})\end{array}$ & $17 \% \mathrm{FO}$ & $20 \% \mathrm{CO}$ & $\begin{array}{c}10 \% \text { FO } \\
(\% \text { of total })\end{array}$ & $17 \% \mathrm{FO}$ \\
\hline \multicolumn{7}{|l|}{ Plasma } \\
\hline C14:0 (myristic) & $23.9 \pm 3.48$ & $29.6 \pm 1.98$ & $45.9 \pm 12.6$ & $0.67 \pm 0.10$ & $0.73 \pm 0.05$ & $1.76 \pm 0.46^{\mathrm{b}, \mathrm{d}}$ \\
\hline C16:0 (palmitic) & $695 \pm 28.6$ & $801 \pm 37.5$ & $585 \pm 66.3^{\mathrm{d}}$ & $19.1 \pm 0.41$ & $19.5 \pm 0.36$ & $21.2 \pm 0.32^{\mathrm{c}, \mathrm{e}}$ \\
\hline C16:1 N7 (palmitoleic) & $30.8 \pm 1.89$ & $70.5 \pm 5.13^{c}$ & $95.1 \pm 11.9^{\mathrm{c}, \mathrm{d}}$ & $0.84 \pm 0.04$ & $1.70 \pm 0.07^{\mathrm{c}}$ & $3.43 \pm 0.14^{\mathrm{c}, \mathrm{e}}$ \\
\hline C16:2 N4 (hexadecadienoic) & $15.4 \pm 4.59$ & $46.3 \pm 2.30^{c}$ & $34.7 \pm 4.61^{\mathrm{b}, \mathrm{d}}$ & $0.43 \pm 0.13$ & $1.14 \pm 0.07^{\mathrm{c}}$ & $1.25 \pm 0.10^{c}$ \\
\hline C18:0 (steric) & $642 \pm 32.4$ & $692 \pm 42.5$ & $414 \pm 52.6^{\mathrm{c}, \mathrm{e}}$ & $17.6 \pm 0.34$ & $16.8 \pm 0.57$ & $14.8 \pm 0.30^{\mathrm{c}, \mathrm{d}}$ \\
\hline C18:1 N9 (oleic) & $243 \pm 17.9$ & $268 \pm 19.1$ & $213 \pm 26.0$ & $6.65 \pm 0.35$ & $6.49 \pm 0.28^{b}$ & $7.62 \pm 0.18^{b}$ \\
\hline C18:1 N7 & $25.4 \pm 3.49$ & $48.4 \pm 2.23^{c}$ & $47.4 \pm 5.96^{\mathrm{c}}$ & $0.70 \pm 0.09$ & $1.18 \pm 0.02^{\mathrm{c}}$ & $1.69 \pm 0.04^{\mathrm{c}, \mathrm{e}}$ \\
\hline C18:2 N6 (linoleic) & $645 \pm 33.2$ & $763 \pm 45.3^{\mathrm{b}}$ & $344 \pm 41.8^{\mathrm{c}, \mathrm{e}}$ & $17.7 \pm 0.49$ & $18.5 \pm 0.32$ & $12.3 \pm 0.21^{\mathrm{c}, \mathrm{e}}$ \\
\hline C20:4 N6 (arachidonic) & $1140 \pm 70.0$ & $807 \pm 48.3^{c}$ & $340 \pm 41.5^{\mathrm{c}, \mathrm{e}}$ & $31.3 \pm 0.84$ & $19.7 \pm 0.98^{c}$ & $12.2 \pm 0.24^{\mathrm{c}, \mathrm{e}}$ \\
\hline C20:5 N3 (eicosapentaenoic, EPA) & $30.0 \pm 13.7$ & $244 \pm 24.5^{c}$ & $278 \pm 37.9^{c}$ & $0.74 \pm 0.31$ & $5.88 \pm 0.45^{\mathrm{c}}$ & $9.94 \pm 0.41^{\mathrm{c}, \mathrm{e}}$ \\
\hline C22:5 N3 (Eocosapentaenoic, DPA) & $52.8 \pm 5.17$ & $43.1 \pm 3.92$ & $51.3 \pm 6.20$ & $1.44 \pm 0.12$ & $1.04 \pm 0.07^{\mathrm{b}}$ & $1.86 \pm 0.07^{\mathrm{b}, \mathrm{e}}$ \\
\hline C22:6 N3 (docosahexaenoic, DHA) & $94.8 \pm 7.02$ & $305 \pm 59.1^{\mathrm{c}}$ & $330 \pm 39.4^{\mathrm{c}}$ & $2.59 \pm 0.12$ & $7.33 \pm 1.32^{\mathrm{c}}$ & $11.8 \pm 0.35^{\mathrm{c}, \mathrm{e}}$ \\
\hline Total & $3640 \pm 177$ & $4120 \pm 207$ & $2780 \pm 329^{\mathrm{b}, \mathrm{e}}$ & 100 & 100 & 100 \\
\hline Saturated & $1360 \pm 57.1$ & $1520 \pm 76.1$ & $1040 \pm 121^{\mathrm{b}, \mathrm{e}}$ & $37.4 \pm 0.49$ & $37.0 \pm 0.72$ & $37.8 \pm 0.39$ \\
\hline Mono-unsaturated & $304 \pm 17.5$ & $387 \pm 25.6$ & $355 \pm 43.3$ & $8.34 \pm 0.31$ & $9.37 \pm 0.34^{b}$ & $12.7 \pm 0.31^{\mathrm{c}, \mathrm{e}}$ \\
\hline N3 & $178 \pm 22.1$ & $593 \pm 64.2^{c}$ & $659 \pm 81.2^{\mathrm{c}}$ & $4.77 \pm 0.42$ & $14.3 \pm 1.26^{\mathrm{c}}$ & $23.6 \pm 0.43^{c, e}$ \\
\hline N6 & $1790 \pm 91.9$ & $1570 \pm 79.6$ & $685 \pm 82.8^{\mathrm{c}, \mathrm{e}}$ & $49.0 \pm 0.49$ & $38.2 \pm 0.76^{c}$ & $24.6 \pm 0.24^{\mathrm{c}, \mathrm{e}}$ \\
\hline N3:N6 & $0.10 \pm 0.01$ & $0.38 \pm 0.04^{c}$ & $0.96 \pm 0.02^{\mathrm{c}, \mathrm{e}}$ & - & - & - \\
\hline \multicolumn{7}{|l|}{ Mammary } \\
\hline C14:0 (myristic) & $66.6 \pm 4.18$ & $52.9 \pm 3.42$ & $58.7 \pm 5.17$ & $4.02 \pm 0.23$ & $4.37 \pm 0.23$ & $5.93 \pm 0.50^{\mathrm{c}, \mathrm{d}}$ \\
\hline C16:0 (palmitic) & $45.6 \pm 3.04$ & $109 \pm 4.26^{c}$ & $149 \pm 4.47^{\mathrm{c}, \mathrm{e}}$ & $2.78 \pm 0.21$ & $9.07 \pm 0.49^{c}$ & $15.1 \pm 0.47^{\mathrm{c}, \mathrm{e}}$ \\
\hline C16:1 N7 (palmitoleic) & $4.35 \pm 1.05$ & $6.52 \pm 0.84$ & $11.8 \pm 1.90^{\mathrm{c}, \mathrm{d}}$ & $0.26 \pm 0.06$ & $0.54 \pm 0.07$ & $1.20 \pm 0.19^{\mathrm{c}, \mathrm{e}}$ \\
\hline C18:0 (steric) & $58.8 \pm 2.46$ & $55.8 \pm 1.56$ & $50.7 \pm 1.32^{\mathrm{b}}$ & $3.56 \pm 0.14$ & $4.61 \pm 0.10^{c}$ & $5.14 \pm 0.12^{\mathrm{c}, \mathrm{d}}$ \\
\hline C18:1 N9 (oleic) & $590 \pm 9.23$ & $402 \pm 16.5^{c}$ & $267 \pm 4.26^{\mathrm{c}, \mathrm{e}}$ & $35.8 \pm 0.20$ & $33.2 \pm 0.82^{\mathrm{b}}$ & $27.1 \pm 0.47^{\mathrm{c}, \mathrm{e}}$ \\
\hline C18:1 N7 & $0.00 \pm 0.00$ & $15.0 \pm 5.69^{\mathrm{b}}$ & $36.6 \pm 5.52^{\mathrm{c}, \mathrm{d}}$ & $0.00 \pm 0.00$ & $1.23 \pm 0.47^{\mathrm{b}}$ & $3.73 \pm 0.57^{\mathrm{c}, \mathrm{e}}$ \\
\hline C18:2 N6 (linoleic) & $833 \pm 17.6$ & $455 \pm 20.3^{c}$ & $218 \pm 10.3^{\mathrm{c}, \mathrm{e}}$ & $50.5 \pm 0.30$ & $37.5 \pm 0.71^{\mathrm{c}}$ & $22.2 \pm 1.16^{\mathrm{c}, \mathrm{e}}$ \\
\hline C18:3 N4 & $14.4 \pm 0.56$ & $16.5 \pm 0.55^{\mathrm{b}}$ & $19.3 \pm 0.90^{\mathrm{c}, \mathrm{d}}$ & $0.87 \pm 0.04$ & $1.37 \pm 0.05^{\mathrm{c}}$ & $1.96 \pm 0.10^{\mathrm{c}, \mathrm{e}}$ \\
\hline C20:4 N6 (arachidonic) & $25.2 \pm 1.84$ & $8.88 \pm 0.58^{c}$ & $10.6 \pm 1.20^{\mathrm{c}}$ & $1.53 \pm 0.12$ & $0.74 \pm 0.04^{c}$ & $1.08 \pm 0.12^{\mathrm{b}, \mathrm{d}}$ \\
\hline C20:5 N3 (eicosapentaenoic, EPA) & $6.78 \pm 2.72$ & $27.7 \pm 2.68^{b}$ & $60.3 \pm 9.75^{\mathrm{c}, \mathrm{e}}$ & $0.41 \pm 0.16$ & $2.31 \pm 0.25^{\mathrm{b}}$ & $6.07 \pm 0.91^{\mathrm{c}, \mathrm{e}}$ \\
\hline \multicolumn{7}{|l|}{ C22:5 N3 (Eocosapentaenoic, DPA) } \\
\hline $1.37 \pm 0.89$ & $15.6 \pm 1.50^{c}$ & $25.9 \pm 3.44^{\mathrm{c}, \mathrm{d}}$ & $0.08 \pm 0.05$ & $1.29 \pm 0.11^{\mathrm{c}}$ & $2.41 \pm 0.32^{\mathrm{c}, \mathrm{e}}$ & \\
\hline C22:6 N3 (docosahexaenoic, DHA) & $2.48 \pm 1.50$ & $45.1 \pm 3.48^{\mathrm{c}}$ & $73.6 \pm 5.13^{\mathrm{c}, \mathrm{e}}$ & $0.15 \pm 0.09$ & $3.73 \pm 0.27^{c}$ & $7.44 \pm 0.44^{c, e}$ \\
\hline Total & $1650 \pm 29.4$ & $1210 \pm 38.4^{c}$ & $987 \pm 13.5^{\mathrm{ce} e}$ & 100 & 100 & 100 \\
\hline Saturated & $171 \pm 5.96$ & $218 \pm 6.64^{c}$ & $258 \pm 6.00^{\mathrm{c}, \mathrm{e}}$ & $10.4 \pm 0.26$ & $18.0 \pm 0.62^{\mathrm{c}}$ & $26.2 \pm 0.50^{\mathrm{c}, \mathrm{e}}$ \\
\hline Mono-unsaturated & $594 \pm 9.25$ & $423 \pm 16.3^{c}$ & $316 \pm 4.80^{\mathrm{c}, \mathrm{e}}$ & $36.0 \pm 0.23$ & $35.0 \pm 0.62$ & $32.0 \pm 0.67^{\mathrm{c}, \mathrm{e}}$ \\
\hline N3 & $10.6 \pm 4.25$ & $88.5 \pm 6.99^{c}$ & $158 \pm 16.0^{\mathrm{c}, \mathrm{e}}$ & $0.65 \pm 0.25$ & $7.33 \pm 0.58^{c}$ & $15.9 \pm 1.42^{\mathrm{c}, \mathrm{e}}$ \\
\hline N6 & $858 \pm 17.4$ & $464 \pm 20.6^{c}$ & $229 \pm 10.8^{\mathrm{c}, \mathrm{e}}$ & $52.0 \pm 0.28$ & $38.3 \pm 0.72^{\mathrm{c}}$ & $23.3 \pm 1.20^{\mathrm{c}, \mathrm{e}}$ \\
\hline N3:N6 & $0.01 \pm 0.005$ & $0.19 \pm 0.01^{\mathrm{b}}$ & $0.70 \pm 0.09^{\mathrm{c}, \mathrm{e}}$ & - & - & - \\
\hline
\end{tabular}

${ }^{\mathrm{a} D a t a}$ represent means $\pm \mathrm{SE}, \mathrm{n}=9-10$ per group. ${ }^{\mathrm{b}}$ Significantly different from corn oil group, $\mathrm{P}<0.05 ;{ }^{\mathrm{c}} \mathrm{P}<0.001$. ${ }^{\mathrm{d}}$ Significantly different from $10 \%$ fish oil group, $\mathrm{P}<0.05 ;{ }^{\mathrm{e}} \mathrm{P}<0.001$.

plasma or per $\mathrm{g}$ of tissue) and relative concentrations (percent of total fatty acids), for rats in each of the 3 diet groups $(20 \%$ $\mathrm{CO}, 10 \% \mathrm{FO}+10 \% \mathrm{CO}$ and $17 \% \mathrm{FO}+3 \% \mathrm{CO}$ ) (Table IV).
Quantitative data are provided for the 12 most abundant fatty acids for both tissue and plasma, representing $>90 \%$ of the total fatty acid pool. As expected dose responsive increases 
Table V. Time course study of the effects of different diets and Tamoxifen on the histology of mammary glands from MNU-treated rats. ${ }^{\mathrm{a}}$

\begin{tabular}{|c|c|c|c|c|c|c|c|}
\hline \multirow[b]{2}{*}{ Experimental groups } & \multicolumn{7}{|c|}{ Histology } \\
\hline & Normal & Mild IDP & Moderate IDP & Florid IDP & DCIS & AC-DCIS & $\mathrm{AC}$ \\
\hline \multicolumn{8}{|l|}{ A, 21 days after $\mathrm{MNU}$} \\
\hline $20 \% \mathrm{CO}$ & 1 & 15 & 32 & 11 & 0 & 0 & 0 \\
\hline $20 \% \mathrm{CO}+\mathrm{TAM}$ & 1 & 7 & 28 & 14 & 2 & 0 & 0 \\
\hline $17 \% \mathrm{FO}$ & 2 & 12 & 21 & 20 & 1 & 0 & 0 \\
\hline $17 \% \mathrm{FO}+\mathrm{TAM}$ & 0 & 9 & 27 & 14 & 0 & 0 & 0 \\
\hline $10 \% \mathrm{FO}$ & 1 & 5 & 23 & 20 & 1 & 0 & 0 \\
\hline $10 \% \mathrm{FO}+\mathrm{TAM}$ & 0 & 17 & 23 & 12 & 2 & 0 & 0 \\
\hline \multicolumn{8}{|l|}{$\mathrm{B}, 28$ days after $\mathrm{MNU}$} \\
\hline $20 \% \mathrm{CO}$ & 7 & 15 & 19 & 9 & 4 & 0 & 0 \\
\hline $20 \% \mathrm{CO}+\mathrm{TAM}$ & 6 & 12 & 19 & 14 & 1 & 4 & 0 \\
\hline $17 \% \mathrm{FO}$ & 2 & 7 & 25 & 13 & 2 & 0 & 1 \\
\hline $17 \% \mathrm{FO}+\mathrm{TAM}$ & 6 & 11 & 23 & 10 & 2 & 1 & 1 \\
\hline $10 \% \mathrm{FO}$ & 4 & 10 & 23 & 8 & 0 & 0 & 1 \\
\hline $10 \% \mathrm{FO}+\mathrm{TAM}$ & 12 & 15 & 16 & 10 & 1 & 0 & 1 \\
\hline \multicolumn{8}{|l|}{$\mathrm{C}, 35$ days after $\mathrm{MNU}$} \\
\hline $20 \% \mathrm{CO}$ & 8 & 19 & 21 & 1 & 3 & 2 & 2 \\
\hline $20 \% \mathrm{CO}+\mathrm{TAM}$ & 6 & 19 & 21 & 5 & 0 & 3 & 2 \\
\hline $17 \% \mathrm{FO}$ & 7 & 9 & 24 & 7 & 2 & 2 & 1 \\
\hline $17 \% \mathrm{FO}+\mathrm{TAM}$ & 9 & 16 & 22 & 5 & 3 & 1 & 0 \\
\hline $10 \% \mathrm{FO}$ & 12 & 12 & 15 & 6 & 3 & 2 & 3 \\
\hline $10 \% \mathrm{FO}+\mathrm{TAM}$ & 10 & 9 & 22 & 6 & 4 & 2 & 1 \\
\hline
\end{tabular}

Following MNU administration (50 mg/kg/i.p.) at 21 days of age, separate groups of rats ( $\mathrm{n}=11 /$ group) were randomly assigned to the indicated diets with and without Tamoxifen (100 $\mu \mathrm{g} / \mathrm{kg} / \mathrm{s} . c .5$ days $/$ week) for 21 (A), 28 (B) or 35 (C) days. At sacrifice, two abdominal inguinal mammary fat pads were excised from each rat and processed for histologic analysis as described in Materials and methods. Between 45 and 59 sections/ group were analyzed and histologically classified as shown. The numbers represent the number of histologic subtypes scored within each group.

in omega-3 fatty acids levels were observed in both tissue and plasma with increasing levels of FO in the diet, with total omega-3 fatty acids increasing from 8.3- to 14.9-fold in the $10 \%$ and $17 \%$ FO groups, respectively compared to the $20 \%$ $\mathrm{CO}$ group in mammary tissue. Comparable increases were also observed in n-3:n-6 ratios in both mammary tissue and plasma. Increasing dietary fish oil also resulted in decreases in mammary and plasma levels of many of the most abundant omega- 6 fatty acids including linoleic and arachidonic acids.

Effects of $\mathrm{FO}$ rich diets and/or Tam on mammary gland histology, Ki67 and cleaved caspase-3 expression. Table V depicts the histology of the mammary glands of the rats fed with the different diets in the presence and in the absence of Tam treatment. Neither FO rich diets nor Tam individually or in combination significantly affected the development of early preneoplastic lesions. This finding is consistent with our previous observation suggesting that these interventions inhibit carcinogenesis by blocking the transition from hyperplasia to carcinoma (1).

FO rich diets suppressed in a dose-dependent fashion Ki67 expression in hyperplastic lesions (Fig. 6A) while they did not affect cleaved caspase-3 (Fig. 6B). Tam treatment did not alter either parameter (data not shown).

Effects of dietary FO and Tam on oxidative stress. The effects of dietary FO and/or Tam on systemic and mammary-specific biomarkers of oxidative stress were examined in MNU treated rats (Fig. 7). Overall, there was little effect of fish oil on either systemic biomarkers of oxidative modifications to proteins (plasma protein carbonyls and blood protein-bound GSH) (Fig. 7A) or for mammary-specific biomarkers based on oxidative damage to DNA (8-OHdG) and lipid peroxidation (TBARS), (Fig. 7B). However, a significant decrease in 8 -isoprostane levels was observed in FO-fed rats for all timepoints $(\mathrm{p}<0.0001)$ with both $10 \%$ and $17 \%$ FO decreasing 

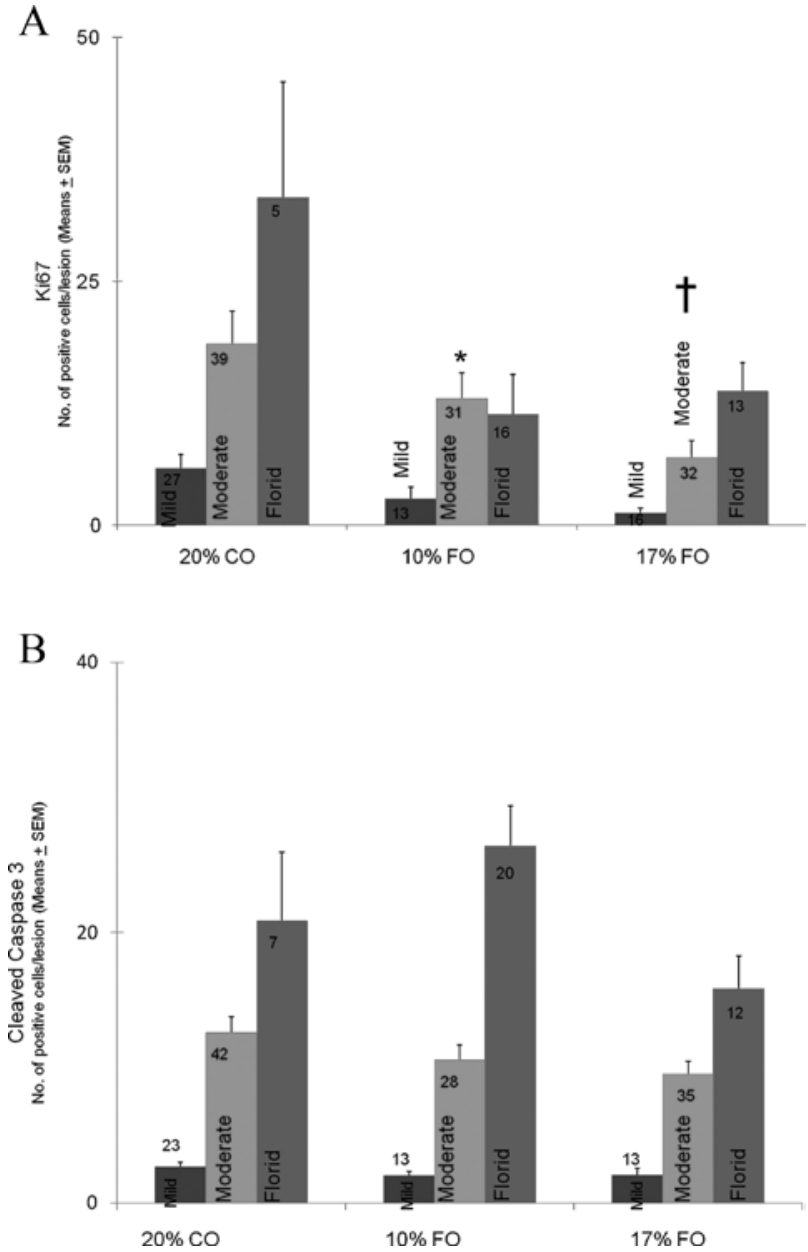

Figure 6. Dietary influences on the expression of Ki67 (A) and cleaved caspase 3 (B). Experimental conditions are as described in the footnote to Table V and in Materials and methods. Data from days 21, 28, and 35 are combined to increase the power of the analysis since there was no influence of time on treatmen effects. Data from Tamoxifen treated groups are omitted for clarity of presentation since Tamoxifen did not alter the expression of either parameter. For each lesion (number of lesions shown in the bars), the number of positively stained cells in three random fields ( $\mathrm{x} 400$ ) was recorded and averaged. ${ }^{*} \mathrm{p}=0.05$ vs. $20 \%$ $\mathrm{CO} ;{ }^{\dagger} \mathrm{p}<0.03$ vs. $20 \% \mathrm{CO}$. The effect of the FO rich diets on Ki67 expression by mild and florid hyperplastic lesions was of borderline statistical significance $(\mathrm{p}=0.06)$, probably as a result of the smaller sample size.

8-isoprostane levels to a similar extent. No effects of Tam on any of these biomarkers were observed (data not shown).

Effects of dietary FO and Tam on mammary GPX activity and GSH levels. We also examined the effects of FO and Tam on the mammary gland antioxidant system involving GPX and its major substrate, GSH (Fig. 8). For GPX, in the 10\% FO group, significant increases ranging from 34 to $100 \%$ were observed over control values at the $21-35$ day time-points $(\mathrm{p}<0.001)$. In contrast to GPX activity, levels of GSH were significantly decreased in the $10 \%$ FO group by 45 to $58 \%$ compared to $20 \%$ CO for the 21-35 day time-points, respectively $(\mathrm{p}<0.01)$. While GSH levels tended to be lower in the $17 \%$ FO group as well, these differences did not reach the level of statistical significance $(\mathrm{p}=0.07)$. Tamoxifen had no effect on either GPX activity or GSH levels, except for small decreases in of 13-28\% at days 21-35 ( $\mathrm{p}<0.05)$ (data not shown).

\section{Discussion}

Targeting the estrogen receptor (ER) with the antiestrogens Tam and raloxifene reduces the incidence of $\mathrm{ER}^{+}$breast cancer by 50 and $38 \%$, respectively (13). However, the wide applicability of these interventions to the population of women at large is limited by their toxicity such as thromboembolic events which, although rare, are significant when considering these drugs are given to healthy women for prevention.

Furthermore, neither Tam nor raloxifene reduce the incidence of ER tumors (13), which are more aggressive and associated with a shorter survival compared to $\mathrm{ER}^{+}$cancers. In the attempt to improve our ability to prevent breast cancer, many investigators are testing a variety of multi-targeted approaches (14) since breast cancer development requires the coordinated activation of oncogenic signals and inactivation of tumor suppressing pathways.

Our laboratories have focused on testing the combination of antiestrogens with an n-3 PUFA rich diet based on the known crosstalk between the ER and the PPAR $\gamma$ receptors leading to enhanced breast cancer suppressive effects when they are simultaneously inhibited by antiestrogens and activated by PPAR $\gamma$ agonists (such as n-3 PUFA), respectively (15).

Using a prepubertal model of MNU-induced rat mammary carcinogenesis, we have recently reported that administration of a FO rich diet potentiated the chemopreventive effect of Tam (1). In order to elucidate mechanisms of antitumor action, we have used the same experimental system to test early host-related and target tissue effects of two FO oil rich diets individually and in combination with Tam in the first five weeks after MNU administration, prior to the development of palpable tumors.

We observed that none of our interventions affected the development of preneoplastic lesions, in agreement with our previous findings that they exert their tumor suppressive effect distally in the carcinogenic process by blocking the transition from hyperplasia to carcinoma (1).

At variance with our results, Ting et al (16) concluded that Tam prevents premalignant changes of the breast in a DMBA model of mammary carcinogenesis in Fischer 344 rats. This discrepancy, however, is not surprising since, in their system, the dysplastic histologic changes inhibited by Tam were induced by concomitant exogenous estrogen administration. We conducted our experiments instead in intact rats in the absence of exogenous hormonal perturbation.

While we did not observe any effect of Tam on Ki67 expression by preneoplastic lesions, Osborne et al (17) reported that Tam administration reduced the thymidine labeling index in the terminal ducts and terminal end buds of the non-tumorous mammary glands of control rats as well as rats injected with MNU at 50 day of age. Although their results suggest that inhibition of proliferation of preneoplastic lesions may mediate the chemopreventive effect of Tam, the effects of the drug on either the number or the histology of the preneoplastic lesions were not reported. Thus a full comparison of their data with ours cannot be made. Furthermore, a major difference in the hormonal milieu of the two experimental systems (post-pubertal vs. prepubertal) could account for the differences in Tam effects on the proliferative activity of the mammary glands. 
A
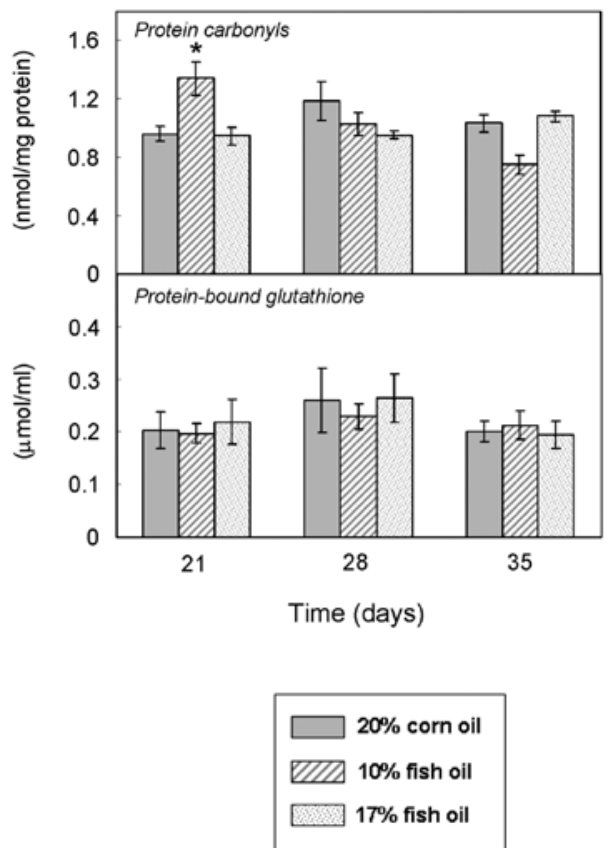

B

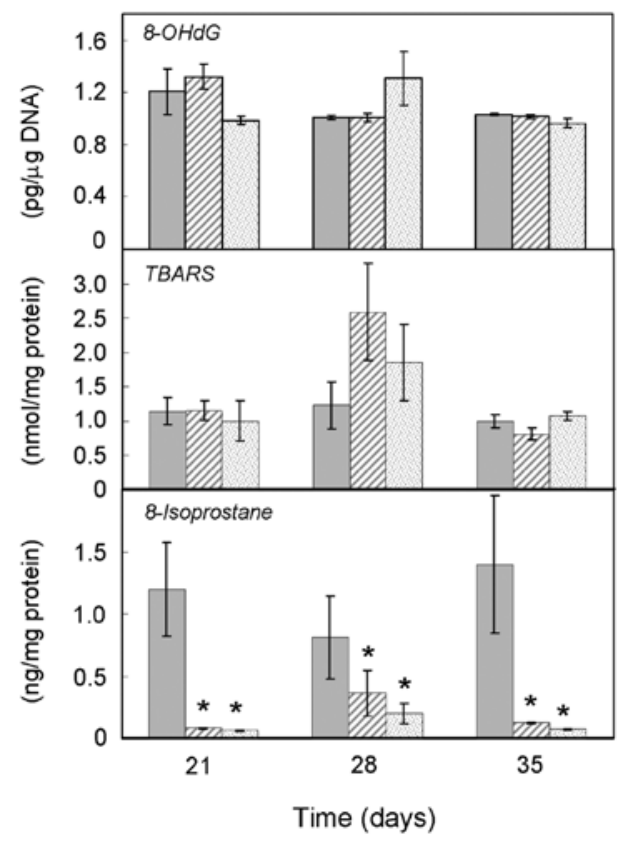

* Significantly different from $20 \%$ CO group $(P<0.05)$

Figure 7. Effect of fish oil on biomarkers of oxidative stress. Groups of rats were fed diets containing $20 \% \mathrm{CO}, 10 \% \mathrm{FO}+10 \% \mathrm{CO}$, or $17 \% \mathrm{FO}+3 \% \mathrm{CO}$ beginning at 20 days of age. MNU was administered at 21 days of age and rats were sacrificed at the indicated times thereafter. (A) Blood was obtained by cardiac puncture using EDTA as an anticoagulant. Protein bound GSH was analyzed in MPA extracts of whole blood ( $\mathrm{n}=6-7$ rats per group) and protein carbonyls were analyzed in plasma ( $\mathrm{n}=3$ per group). (B) A single abdominal inguinal mammary fat pad from each rat was excised and processed by homogenization and centrifugation to obtain cell-free extracts. 8-Isoprostanes were determined by ELISA and TBARS were analyzed spectrophotometrically ( $\mathrm{n}=3-4$ per group). Another abdominal inguinal mammary fat pad was excised and processed by homogenization and centrifugation to obtain nuclear pellets from which DNA was extracted. $8-\mathrm{OHdG}$ was determined by ELISA ( $\mathrm{n}=3-4$ per group). Methodological details are provided in Materials and methods. Bars represent mean \pm SEM.

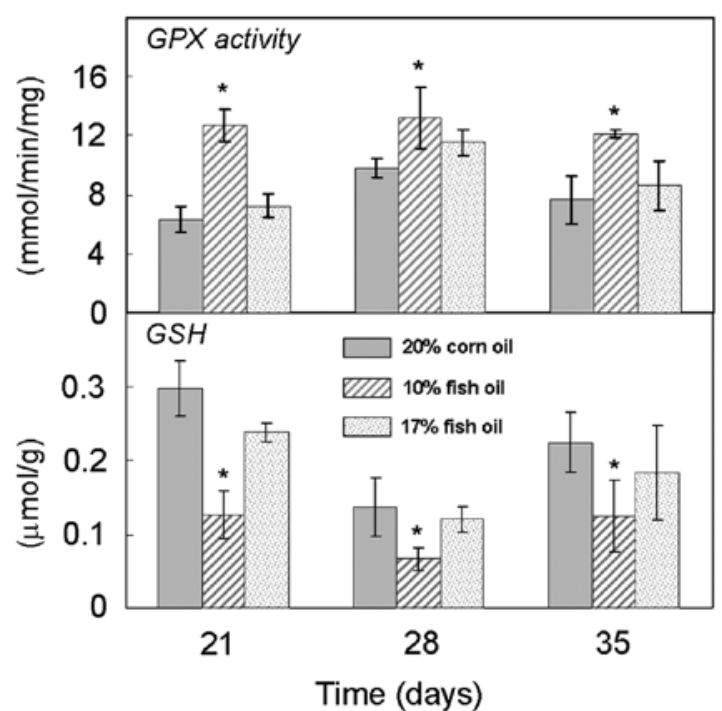

* Significantly different from $20 \% \mathrm{CO}$ group $(\mathrm{P}<0.001)$

Figure 8. Effect of fish oil on mammary GPX activity and GSH levels. Groups of rats $(n=4)$ were fed diets containing $20 \% \mathrm{CO}, 10 \% \mathrm{FO}+10 \% \mathrm{CO}$, or $17 \% \mathrm{FO}+3 \% \mathrm{CO}$ beginning at 20 days of age. $\mathrm{MNU}$ was administered at 21 days of age and rats were sacrificed at the indicated times thereafter. A single abdominal inguinal mammary fat pad from each rat was excised and processed by homogenization and centrifugation to obtain cell-free extracts GPX activity was determined using cumene hydroperoxide as a substrate. Another abdominal inguinal fat pad from each rat was excised and processed by homogenization in MPA for GSH analysis. Methodological details are provided in Materials and methods. Bars represent mean \pm SEM.
FO, in general, has been shown to have a tumor suppressive effect in experimental models of breast cancer $(18,19)$. We observed that in our experimental system, FO did not inhibit the development of preneoplastic lesions. Although we observed a decrease in proliferative activity reflected by a reduction in Ki67, we found no effect of FO on apoptosis and ultimately on the number of hyperplasias. At variance with our findings, Manna et al (20) found that FO administration to inbred Sprague Dawley rats injected with DMBA inhibited the development of hyperplasia in conjunction with inhibition of proliferation and induction of apoptosis in the mammary gland. It should be pointed out that in the experimental system used by Manna and his collaborators (20), FO administration had a much more profound inhibitory effect on mammary carcinogenesis than observed in our system, which may in part explain the difference between their findings and ours on FO effects on the development of hyperplastic lesions.

Our findings that omega-3:omega- 6 fatty acid ratios increased in a dose-dependant fashion to increasing concentrations of dietary FO in both plasma and mammary tissue confirm the efficacy of the dietary interventions at impacting the fatty acid composition of the target tissue, and further indicate that plasma profiles may be used as a marker for fatty acid changes in the mammary tissue. In addition, our observation that increases in specific FO-derived omega- 3 fatty acids (EPA and DHA) in FO-fed rats are accompanied by decreases in certain omega- 6 fatty acids, most notably arachidonic acid, suggest that FO 
effects may not be only driven by omega- 3 fatty acid changes but perhaps changes in other FA as well. Our results of fatty acid profiles in mammary tissues are similar those observed previously resulting from administration of $\mathrm{FO}$ or specific FO-derived fatty acids to Sprague-Dawley rats $(21,22)$.

A major focus of our experiments was to determine the impact of FO on levels of oxidative stress in mammary tissue. Numerous potential mechanisms for omega-3 fatty acids have been proposed including their role in protecting against oxidative stress and inflammation (23). Both increases and decreases in oxidative stress have been observed as a result of FO administration (24). However, there have been few studies in mammary tissue where multiple targets of oxidative damage were investigated. Our study is unique in addressing a comprehensive and systematic battery of systemic as well as mammary specific oxidative stress-related biomarkers, since oxidative stress can potentially impact mammary carcinogenesis via a variety of mechanisms involving damage or alterations to cellular macromolecules including DNA, lipids and proteins. Overall, our results suggest that during early stages of tumorigenesis FO, as well as Tam, have little or no effect on either systemic or mammary-specific levels of oxidative stress. While 8-isoprostane levels were decreased as a result of FO administration, this is likely due to a reduction in arachidonic acid levels as opposed to a decrease in lipid peroxidation since these prostaglandin-like compounds are formed through the nonenzymatic oxidation of arachidonic acid in cell membranes $(25,26)$. Indeed, as described above, we observed large decreases in arachidonic acid levels in both mammary tissue and plasma as a result of fish oil feeding (Table IV). Overall these findings indicate that potential protective effects of FO are not likely driven by a reduction or increase in levels of oxidative stress, but that changes in arachidonic acid specific pathways may be playing a role.

The effects of $10 \%$ FO on GPX activity may represent a protective effect of $10 \%$ FO via mechanisms involving peroxide scavenging as well as regulation of critical cell signaling mechanisms $(27,28)$. Induction of GPX activity by fish oil has been previously observed in numerous in vitro and in vivo studies (29-31). The importance of GPX in prevention against mammary cancer has been highlighted by results of epidemiology studies linking specific polymorphisms in GPX genes with breast cancer development (32). However, the relationship is complex, depending on numerous factors such as stage of carcinogenesis and GPX isoenzyme (27). Our finding that GPX is induced specifically in the $10 \%$ FO group is of particular interest given the previous finding of a protective effect for an $11 \%$ but not $18 \%$ menhaden oil diet against MNU-induced mammary carcinogenesis in F344 rats (2). It was of interest that the observed increases in GPX activity were accompanied by a decrease in GSH levels in the $10 \%$ FO group. This might be explained by an increase in GSH utilization as a result of enhanced GPX activity.

In conclusion, these results suggest that FO and/or Tam have no major effects on systemic or mammary gland specific biomarkers of oxidative stress. FO appeared to exert an antiproliferative effect in the preneoplastic lesions as supported by the reduction in Ki67 expression. The effects of FO may result from changes in arachidonic acid specific pathways.

\section{Acknowledgments}

This work was supported by Susan G. Komen for the Cure, Grant no. KG081632.

\section{References}

1. Manni A, Xu H, Washington S, et al: The impact of fish oil on the chemopreventive efficacy of tamoxifen against development of $\mathrm{N}$-methyl-N-nitrosourea-induced rat mammary carcinogenesis. Cancer Prev Res 3: 322-330, 2010.

2. Cohen LA, Chen-Backlund JY, Sepkovic DW and Sugie S: Effect of varying proportions of dietary menhaden and corn oil on experimental rat mammary tumor promotion. Lipids 28 : 449-456, 1993.

3. Wei N, Wang B, Zhang QY, et al: Effects of different dietary fatty acids on the fatty acid compositions and the expression of lipid metabolic-related genes in mammary tumor tissues of rats. Nutr Cancer 60: 810-825, 2008.

4. Thompson HJ, Singh M and McGinley J: Classification of premalignant and malignant lesions developing in the rat mammary gland after injection of sexually immature rats with 1-methyl1-nitrosourea. J Mammary Gland Biol Neoplasia 5: 201-210, 2000.

5. Paglia DE and Valentine WN: Studies on the quantitative and qualitative characterization of erythrocyte glutathione peroxidase. J Lab Clin Med 70: 158-169, 1967.

6. Richie JP Jr, Skowronski L, Abraham P and Leutzinger Y: Blood glutathione concentrations in a large-scale human study. Clin Chem 42: 64-70, 1996.

7. Lepage $\mathrm{G}$ and Roy CC: Direct transesterification of all classes of lipids in a one-step reaction. J Lipid Res 27: 114-120, 1986.

8. Oliver CN, Ahn BW, Moerman EJ, Goldstein S and Stadtman ER: Age-related changes in oxidized proteins. J Biol Chem 262: 5488-5491, 1987.

9. Muscat JE, Kleinman W, Colosimo S, et al: Enhanced protein glutathiolation and oxidative stress in cigarette smokers. Free Radic Biol Med 36: 464-470, 2004.

10. Thompson HJ and Adlakha H: Dose-responsive induction of mammary gland carcinomas by the intraperitoneal injection of 1-methyl-1-nitrosourea. Cancer Res 51: 3411-3415, 1991.

11. Wallen WJ, Belanger MP and Wittnich C: Sex hormones and the selective estrogen receptor modulator tamoxifen modulate weekly body weights and food intakes in adolescent and adult rats. J Nutr 131: 2351-2357, 2001.

12. Wallen WJ, Belanger MP and Wittnich C: Body weight and food intake profiles are modulated by sex hormones and tamoxifen in chronically hypertensive rats. J Nutr 132: 2246-2250, 2002.

13. Vogel VG, Costantino JP, Wickerham DL, et al: Update of the National Surgical Adjuvant Breast and Bowel Project Study of Tamoxifen and Raloxifene (STAR) P-2 Trial: preventing breast cancer. Cancer Prev Res 3: 696-706, 2010.

14. Li Y and Brown PH: Prevention of ER-negative breast cancer. In: Cancer Prevention II: Recent Results in Cancer Research. Senn HJ, et al. (ed.) Springer-Verlag, Berlin, Heidelberg, pp121-134, 2009.

15. Bonofiglio D, Gabriele S, Aquila S, et al: Estrogen receptor alpha binds to peroxisome proliferator-activated receptor response element and negatively interferes with peroxisome proliferatoractivated receptor gamma signaling in breast cancer cells. Clin Cancer Res 11: 6139-6147, 2005.

16. Ting AY, Kimler BF, Fabian CJ and Petroff BK: Tamoxifen prevents premalignant changes of breast, but not ovarian, cancer in rats at high risk for both diseases. Cancer Prev Res 1: 546-553, 2008.

17. Osborne MP, Ruperto JF, Crowe JP, Rosen PP and Telang NT: Effect of tamoxifen on preneoplastic cell proliferation in $\mathrm{N}$-nitroso-N-methylurea-induced mammary carcinogenesis. Cancer Rres 52: 1477-1480, 1992.

18. Rose DP and Connolly JM: Omega-3 fatty acids as cancer chemopreventive agents. Pharmacol Therapeut 83: 217-244, 1999.

19. Lupton $\mathbf{J}$ and Chapkin R: Chemopreventive effects of omega-3 fatty acids. In: Cancer Chemoprevention. Vol. 1: Promising Cancer Chemopreventive Agents. Kelloff G, Hawk, ET and Segman CC (eds.) The Human Press, Inc., Totowa, NJ, pp591-608, 2004. 
20. Manna S, Chakraborty T, Ghosh B, et al: Dietary fish oil associated with increased apoptosis and modulated expression of Bax and Bcl-2 during 7,12-dimethylbenz(alpha)anthracene-induced mammary carcinogenesis in rats. Prostag Leukotr Ess 79: 5-14, 2008.

21. Colas S, Paon L, Denis F, et al: Enhanced radiosensitivity of rat autochthonous mammary tumors by dietary docosahexaenoic acid. Int J Cancer 109: 449-454, 2004.

22. Takata T, Minoura T, Takada H, et al: Specific inhibitory effect of dietary eicosapentaenoic acid on N-nitroso-N-methylureainduced mammary carcinogenesis in female Sprague-Dawley rats. Carcinogenesis 11: 2015-2019, 1990.

23. Chapkin RS, Kim W, Lupton JR and McMurray DN: Dietary docosahexaenoic and eicosapentaenoic acid: emerging mediators of inflammation. Prostag Leukotr Ess 81: 187-191, 2009.

24. Calviello G, Serini S, Piccioni E and Pessina G: Antineoplastic effects of $n-3$ polyunsaturated fatty acids in combination with drugs and radiotherapy: preventive and therapeutic strategies. Nutr Cancer 61: 287-301, 2009.

25. Morrow JD, Hill KE, Burk RF, Nammour TM, Badr KF and Roberts LJ II: A series of prostaglandin F2-like compounds are produced in vivo in humans by a non-cyclooxygenase, free radicalcatalyzed mechanism. Proc Natl Acad Sci USA 87: 9383-9387, 1990 .
26. Pratico D, Lawson JA, Rokach J and FitzGerald GA: The isoprostanes in biology and medicine. Trends Endocrinol Metab 12: 243-247, 2001.

27. Brigelius-Flohe R and Kipp A: Glutathione peroxidases in different stages of carcinogenesis. Biochim Biophys Acta 1790: 1555-1568, 2009.

28. Fourquet S, Huang ME, D'Autreaux B and Toledano MB: The dual functions of thiol-based peroxidases in $\mathrm{H}_{2} \mathrm{O}_{2}$ scavenging and signaling. Antioxid Redox Signal 10: 1565-1576, 2008.

29. Venkatraman JT, Chandrasekar B, Kim JD and Fernandes G: Effects of n-3 and n- 6 fatty acids on the activities and expression of hepatic antioxidant enzymes in autoimmune-prone NZBxNZW F1 mice. Lipids 29: 561-568, 1994.

30. Crosby AJ, Wahle KW and Duthie GG: Modulation of glutathione peroxidase activity in human vascular endothelial cells by fatty acids and the cytokine interleukin-1 beta. Biochim Biophys Acta 1303: 187-192, 1996.

31. Lemaitre D, Vericel E, Polette A and Lagarde M: Effects of fatty acids on human platelet glutathione peroxidase: possible role of oxidative stress. Biochem Pharmacol 53: 479-486, 1997.

32. Hu YJ and Diamond AM: Role of glutathione peroxidase 1 in breast cancer: loss of heterozygosity and allelic differences in the response to selenium. Cancer Res 63: 3347-3351, 2003. 